\title{
Magnitude and Correlates of Contraceptive Use among Females in Reproductive Age in Arba Minch Zuria Woreda: A Community Based Cross-Sectional Study
}

\author{
Girma Temam Shifa1,2 \\ ${ }^{1}$ Department of Public Health, College of Medicine and Health Sciences, Arba Minch University, Arba Minch, \\ Ethiopia \\ ${ }^{2}$ School of Public Health, Addis Ababa University, Addis Ababa, Ethiopia \\ Email: girmatemam2@yahoo.com
}

Received 1 April 2014; revised 6 May 2014; accepted 13 May 2014

Copyright (C) 2014 by author and Scientific Research Publishing Inc. This work is licensed under the Creative Commons Attribution International License (CC BY). http://creativecommons.org/licenses/by/4.0/ (c) (7)

\begin{abstract}
Background: Despite its positive impact in reducing maternal and child mortality and morbidity, the utilization rate of contraceptives is unacceptably low in many developing countries including Ethiopia. This warrants the investigation of the contributing factors of this low utilization for appropriate interventions. Objective: The objective of this study was to investigate the magnitude and associated factors of contraceptive use in Arba Minch Zuria Woreda, Gamo Gofa Zone, Southern Ethiopia. Methods: A community based cross-sectional study was conducted from April to July 2010 in 9 kebeles of Arba Minch Demographic and Health Development Program. Results: In this study, $28.3 \%$ of all women $\& 32.7 \%$ currently married were using any contraceptive methods during the time of the survey. Almost all current users were using modern methods; the most widely used method was injectable $(24.2 \%)$ followed by implants $(2.4 \%)$ and pills $(1.3 \%)$. Current marital status, ethnicity, age, education, presence of radio set in the house hold and discussion about family planning in the last 6 month before the study with their partner were the independent predictors of contraceptive use. Conclusion: The contraceptive prevalence rate is promising but efforts should continue to further increase the contraceptive coverage especially on kebeles with low coverage by targeting men and misconceptions about family planning.
\end{abstract}

\section{Keywords}

Family Planning, Correlates of Contraceptive Use, Contraception

How to cite this paper: Shifa, G.T. (2014) Magnitude and Correlates of Contraceptive Use among Females in Reproductive Age in Arba Minch Zuria Woreda: A Community Based Cross-Sectional Study. Health, 6, 1263-1276. 


\section{Introduction}

Family planning reduces maternal deaths by spacing and preventing pregnancy. It also enables to have the desired number of children at the desired time. Contraceptive prevalence rate has been considered as indicator of health, population development and women's empowerment [1]. It is also considered as a proxy measure of access to reproductive health services that are essential for meeting many of the Millennium Development Goals (MDG)s, like: child mortality, maternal health, HIV/AIDS, and gender related goals [1]. Despite this fact the utilization rate is low in many developing countries. An estimated 222 million women in developing countries would like to delay or stop childbearing but are not using any method of contraception [2]. The main reasons include inadequate access, lack of knowledge about family planning methods and where programs/services exist, socio demographic \& economic factors etc. [3].

Demographic transition in sub-Saharan Africa is much slower than elsewhere, which could be due to many factors like cultural, economic, political and demographic. The region continues to have strong cultural preference for large families, large rural populations relying on subsistence farming, and low levels of economic development. Moreover, continued high rates of infant and child mortality have contributed to high fertility levels, because many couples may have "extra children” to make up for those who die young [3].

In Ethiopia high population growth continues to induce increased demand for resources and the rate at which these resources are exploited. The population of the country increased from 53.5 million in 1994 to 73,845,035 million in 2007 [4]. In response to this, the country developed a population policy in 1993, with the objective of reducing the total fertility rate per woman to 4.0 and increasing the contraceptive prevalence to $44 \%$ by the year 2015. The strategies to achieve these objectives include, expanding health institution, community based contraceptive distribution and mobilizing public and private resources [5]. In spite of such long history of family planning and these efforts, the country continues to have high total fertility rate (TFR) (5.4) and low contraceptive prevalence rate (CPR) (14.7\%) [6]. There is also a high rate of unintended pregnancy in the country. In a study conducted in Harer Town, Eastern Ethiopia, it was observed that 33.3\% of most recent pregnancies were unintended. The prevalence of unintended childbirth was also reported to be $14.3 \%$ while induced abortion was found to be $14.4 \%$ [7].

Southern nations and nationality people region (SNNPR) is one of the regions with high fertility rate in the country, with TFR of 5.6. Contraceptive prevalence rate and unmet need in the region were also relatively high with 34\% and 37.4\% respectively [6]. Male partner involvement, religion, family income, marital status, age and educational status of the mother, couples communication about family planning, history of child death, quality of the service, parity (number of live children) and age at first marriage are some of determinant factors identified by different researches [8]-[13].

According to Gamo Gofa Zone (where the study district found) heath department 2009 report (unpublished report), the prevalence of family planning in the Zone and Arbaminch Zuria Woreda/District was reported to be 84.56\% and 56.4\% respectively. This is by far higher than the national and regional figures reported by EDHS 2005 (Ethiopian Demographic and Health Survey 2005). This may not show the actual prevalence rate as the report was totally dependent on institution based reports which usually suffer from different limitations, like duplication of reports; not all population groups have geographic or economic access to health facilities and those that do have such access are usually self-selected etc.

There was limited knowledge about family planning utilization and its correlates at community level in the study area. This study investigated the magnitude and correlates of contraceptive use at community level.

\section{Methodology}

Study area: The study was conducted in the 9 research kebeles (lower administrative level in Ethiopia) of Arba Minch Demographic and Health Development Program of Arba Minch University which is based in Arba Minch Zuria Woreda/District. Arbaminch Zuria Woreda is one of the 17 woredas in Gamo Gofa Zone. The woreda has 27 kebeles in three climatic \& topographic conditions. The 9 research kebeles of Arba Minch Demographic and Health Development Program are randomly selected from these kebeles after stratifying the woreda in to three climatic zones (Dega, Woyna Dega and Kolla). According to the 2007 national census reports the total population of the woreda reported to be 165,680 (with 82,751 males and 82,929 female) [4]. Two health centers, two developing health centers and 35 health posts were providing health services to the population of the district.

Study design: Community based cross-sectional study design was conducted from April to July 2010. 
Source population: All women of reproductive age in the woreda.

Study population: All women of reproductive age in the woreda who were selected by the set criteria.

Sampling procedure: All kebeles of Arba Minch Demographic and Health Development Program of Arba Minch University were included in the current study. Arba Minch Demographic and Health Development Program is based in 9 randomly selected kebeles of Arba Minch Zuria Woreda (District). Systematic sampling was applied to select the households $(\mathrm{HH})$ and women in reproductive age in these selected HHs were interviewed. If there were two or more eligible in the selected HHs one of them was selected using lottery method and if there were no eligible in the selected $\mathrm{HH}$ the next $\mathrm{HH}$ with eligible was taken.

Sample size determination: A single population proportion was used to determine the sample size by assuming: the prevalence of family planning at 50\% (a value which gives the maximum possible sample size), a standard score corresponding to 95\% confidence level (1.96) and a margin of error (5\%). Accordingly, the sample size calculated was 385. Applying design effect of 2 (as a two stage sampling was implemented) and considering 5\% non response rate, the required sample size was 809.

Data collection: A closed ended structured Amharic questionnaire was utilized for data collection. The questionnaire was developed in English based on literature review and translated in to Amharic, then back to English to check for its consistency. Finally the Amharic version was used for data collection. The main components of the questionnaire were: socio demographic characteristics, sexual history and knowledge and attitude of the respondents towards family planning methods. Eighteen data collectors and 3 supervisors were recruited to supervise the data collection process.

Data quality assurance: A carefully designed questionnaire was translated first into Amharic and back to English to assure its consistency. The questionnaire was pre-tested in a kebele, which was not included in the study to assess the clarity of the questions, their sensitiveness as well as understanding of the data collectors. Discussion was held based on the result of the pre-test and accordingly, some amendments were made. A three days training was given to the supervisors and the data collectors on the procedure. The data was checked for completeness, accuracy, clarity, and consistency by the supervisors and the investigators on daily basis. Any error or ambiguity and incompleteness were corrected accordingly. The data was intensively cleaned up before its analysis.

Data processing and analysis: The data was entered using Epi-info 2002 version 3.4 .2 and analysis was carried out using SPSS-16 statistical packages. Both descriptive and analytic analyses were made. Bivariate and multi variable logistic regression analysis were employed to assess the association between the dependent and independent variables. Odds ratio (OR) with 95\% confidence interval was computed to assess the presence and degree of association between dependent and independent variables. The multi variable analysis was done for the socioeconomic and demographic variables and reproductive and other characteristics separately by using enter method. P-value of 0.05 was set as a cut-off point for the significance of the association between dependent and independent variables.

Ethical considerations: Ethical clearance and approval was obtained from the Ethical Committee of Arba Minch University and letter was written to the woreda/district and respective kebeles and permission was secured at all levels. After explaining about the purpose, the possible benefit and harm of the study and confidentiality, verbal consent was obtained from each respondent. To assure the confidentiality of the response, anonymous interview was conducted.

\section{Result}

\subsection{Socioeconomic and Demographic Characteristics of the Respondents}

A total of 809 female in reproductive age group from nine kebeles were interviewed with a response rate of $100 \%$. Majority of the respondents 695 (85.9\%) were currently married, more than half 478 (59.1\%) of the respondents were age between 20 and 34 years, with the median age of 29 years. Majority of the respondents 496 (61.3\%) were protestants followed by orthodox 265 (32.8). Ethnically, majority 630 (77.9\%) were Gamo followed by Zeise tribe 69 (8.5\%). Regarding educational level of the respondents 513 (63.4\%) were illiterate followed by primary education (Grade 1 to 6) 165 (20.4\%). Only six (0.7\%) were above grade 12. Majority 681 (84.2\%) were house wives and only $11(1.4 \%)$ were government employees.

Five hundred fifty (79.1\%) and 330 (47.5\%) of the husband's of currently married women were farmer and illiterate respectively. Four hundred sixty six (61\%) of the respondents classified their relative income as poor or 
very poor and only 606 (74.9\%) of the respondents able to mention their monthly income. Less than half 376 (46.5\%) of the respondents had Radio in their household and only 59 (7.3\%) of the participants reported to have television set in their household. 579 (71.6\%) of the respondents' resident were within 30 minutes walking distance from the health institution providing family planning services.

\subsection{Reproductive History of the Respondents}

Of 742 ever married women 572 (77.1\%) mentioned/remembered age at first marriage of whom 231 (40.4\%) got married before their $18^{\text {th }}$ birth date. Age at first marriage was ranging from 13 to 26 years with mean (SD) and median age of 18.3 (2.8) and 18 years, respectively. Majority, 724 (89.5\%) of the respondents reported to be ever pregnant. Among currently married women 674 (97.0\%) were ever pregnant at the time of the survey (Table 1). Ninety (11.1\%) of the total respondents were pregnant at the time of the survey. Except one all of them were married at the time of the survey. Eighty (20.0\%) of the current pregnancy were mistimed or unwanted. I thought I couldn’t be pregnant 9 (50\%) and I don't know about family planning methods 4 (22.2\%) were the commonly mentioned reasons for the failure to avoid these mistimed and unintended pregnancies. Only one woman reported method failure as the reason for unintended pregnancy.

One hundred thirty eight (17.1\%) of all women and 134 (19.3\%) of currently married women gave birth within 6 months prior to the survey. Twenty eight (20.0\%) of the pregnancy for these births were mistimed or unwanted (Table 1). I thought I couldn't be pregnant 8 (28.6\%); I don't know about family planning methods 4 (14.3\%) and husband/partner disapproval were the commonly mentioned reasons for not preventing these mistimed and unintended pregnancies. To assess birth interval the gap between preceding live births and the current pregnancy or the pregnancy for live births within 6 months prior to the survey were entertained. Accordingly, 32 (13.9\%) of women became pregnant within 24 months after the preceding live birth.

Of those women who reported to be ever pregnant 539 (74.5\%) reported/remembered their age at first pregnancy of whom 162 (30.1\%) got pregnant for the first time before age of 18 years. Age at first pregnancy was reported as early as 14 years and as late as 29 years with a median age of 19 years. Three hundred seven (37.9\%) and 262 (32.4\%) of the women were grand multi gravida ( $\geq 5$ pregnancy) and grand multi parous ( $\geq 5$ births), respectively. Of those women who reported to be ever pregnant 123 (17.0\%), 29 (4.0\%) and 264 (36.5\%) reported ever history of abortion, still birth and child death, respectively. Among 724 women who reported to be ever pregnant $446(61.6 \%)$ had at least 3 live children at the time of the study (Table 1). Eighteen (2.2\%) of all women and $13(1.9 \%)$ of currently married women want as many children as possible. The mean (SD) ideal number of children wanted was 5.3 (1.6) with the range of 11 - 2 children. The median numbers of male and female children wanted were 3 and 2, respectively.

\subsection{Knowledge and Attitude of the Respondents towards Family Planning Methods}

Out of the total respondents 720 (89.0\%) heard about contraceptive methods. Out of 695 currently married women 632 (90.9\%) heard about contraceptive method. Most of them 554 (68.5\%) heard from Health professionals followed by friends 126 (15.6\%). Reasonably, large number 720 (89.0\%) and 725 (89.6\%) of the respondents want to know more about family planning and support use of contraceptive method by others, respectively. Majority 692 (85.5\%) of the respondents believe modern contraceptives are the best way to prevent unwanted/mistimed pregnancy. Out of the total participants only 338 (41.8\%) have discussed about family planning with her husband/partner during the 6 months prior to the survey, it was 334 (48.1\%) among currently married women. With regard to the decision about family planning, 541 (66.9\%) reported that both partner decide and 50 (6.2\%) by her husband/partner (Table 2). With regard to knowledge about contraceptives, $89.0 \%$ of all and $90.9 \%$ of currently married women know at least one contraceptive method. Modern methods are more widely known than traditional methods. For example, $90.9 \%$ percent of currently married women know of a modern method, and only $17 \%$ know of a traditional method (Table 3 ).

\subsection{Utilization of Contraception and Their Associated Factors}

Three hundred sixty eight (45.6\%) of all women \& $51.7 \%$ of currently married women were ever user of any contraceptive. Whereas, $28.3 \%$ of all women $\& 32.7 \%$ of currently married women were using any contraception during the time of the survey. Except one woman all current users were using modern methods, the most 
Table 1. Reproductive history of women of reproductive age, Arba Minch Zuria Woreda, 2010.

\begin{tabular}{|c|c|c|}
\hline Variable & & \\
\hline Ever be pregnant & Frequency $(n=809)$ & Percent \\
\hline No & 85 & 10.5 \\
\hline Yes & 724 & 89.5 \\
\hline Age at $1^{\text {st }}$ pregnancy & Frequency $(\mathbf{n}=724)$ & Percent \\
\hline$<18$ years & 162 & 22.4 \\
\hline $18-29$ & 377 & 52.1 \\
\hline Not remember/no response & 185 & 25.6 \\
\hline Currently pregnant & Frequency $(n=809)$ & Percent \\
\hline No & 634 & 78.4 \\
\hline Yes & 90 & 11.1 \\
\hline Never pregnant & 85 & 10.5 \\
\hline Classification of the current pregnancy & Frequency $(n=90)$ & Percent \\
\hline Wanted & 72 & 80.0 \\
\hline Wanted but miss timed & 15 & 16.7 \\
\hline Unwanted & 3 & 3.3 \\
\hline Gave birth within 6 months prior to the survey & Frequency $(n=809)$ & Percent \\
\hline Yes & 140 & 17.3 \\
\hline No & 497 & 61.4 \\
\hline Never pregnant/currently pregnant/no response & 172 & 21.3 \\
\hline Pregnancy for the birth in 6 months prior to the survey & Frequency $(n=140)$ & Percent \\
\hline Wanted & 112 & 80.0 \\
\hline Wanted but miss timed & 22 & 15.7 \\
\hline Unwanted & 6 & 4.3 \\
\hline Gaps b/n preceding birth \& the current pregnancy or last 6 month birth & Frequency $(n=230)$ & Percent \\
\hline $1^{\text {st }}$ pregnancy/no response & 58 & 25.2 \\
\hline$<24$ months & 32 & 13.9 \\
\hline 24 - 36 months & 101 & 43.9 \\
\hline$>36$ months & 39 & 14.0 \\
\hline Age at first pregnancy & Frequency $(\mathbf{n}=539)$ & Percent \\
\hline$<18$ & 162 & 30.1 \\
\hline $18-35$ & 377 & 69.9 \\
\hline Number of pregnancies (gravidity) & Frequency $(n=809)$ & Percent \\
\hline $1-2$ & 210 & 26.0 \\
\hline $3-4$ & 207 & 25.6 \\
\hline$>5$ & 307 & 37.9 \\
\hline None (0) & 85 & 10.5 \\
\hline No. of birth (parity) & Frequency $(n=809)$ & Percent \\
\hline $1-2$ & 217 & 26.8 \\
\hline $3-4$ & 218 & 26.9 \\
\hline$>5$ & 262 & 32.4 \\
\hline None/no response & 112 & 13.8 \\
\hline Ever abortion & Frequency $(n=809)$ & Percent \\
\hline No & 601 & 74.3 \\
\hline Yes & 123 & 15.2 \\
\hline Never pregnant & 85 & 10.5 \\
\hline Number of live children & Frequency $(n=809)$ & Percent \\
\hline $1-2$ & 253 & 31.3 \\
\hline $3-4$ & 248 & 30.7 \\
\hline$\geq 5$ & 198 & 24.5 \\
\hline No live child & 110 & 13.6 \\
\hline
\end{tabular}


Table 2. Knowledge and attitude of the respondents, Arbaminch Zuria Woreda, 2010.

\begin{tabular}{|c|c|c|}
\hline Variable & & \\
\hline Heard about contraceptives & Frequency & Percent \\
\hline No & 90 & 11.0 \\
\hline Yes & 720 & 89.0 \\
\hline Heard from & Frequency & Percent \\
\hline Didn’t heard/Don't remember & 92 & 11.4 \\
\hline $1=$ Health workers & 554 & 68.5 \\
\hline 2 = Radio & 8 & 1.0 \\
\hline $3=$ School $/$ Teacher & 23 & 2.8 \\
\hline $4=$ News paper & 1 & .1 \\
\hline $5=$ Friends & 126 & 15.6 \\
\hline $6=$ Others & 5 & .6 \\
\hline Want to know about contraceptive & Frequency & Percent \\
\hline No & 86 & 10.6 \\
\hline Yes & 720 & 89.0 \\
\hline No response & 3 & .4 \\
\hline Support use of contraceptives & Frequency & Percent \\
\hline No & 72 & 8.9 \\
\hline Yes & 725 & 89.6 \\
\hline No response & 12 & 1.5 \\
\hline Best way to prevent unwanted/mistimed pregnancy & Frequency & Percent \\
\hline $1=$ Modern contraceptives & 692 & 85.5 \\
\hline $2=$ Natural methods & 62 & 7.7 \\
\hline 3 = Don’t know & 46 & 5.7 \\
\hline $4=$ No response & 9 & 1.1 \\
\hline Discussed with partner about family planning in the last 6 month & Frequency & Percent \\
\hline No response & 11 & 1.4 \\
\hline yes & 338 & 41.8 \\
\hline No & 391 & 48.3 \\
\hline No partner & 69 & 8.5 \\
\hline
\end{tabular}

widely used method was injectable 196 (24.2\%) followed by implants 19 (2.4\%) and pills 9 (1.3\%) (Table 3). Among currently married current users $76 \%$ were using for spacing and $24 \%$ for limiting. The reasons given by currently married non users, for their non use include: want to have more children by 294 (62.8\%), don't know about family planning method by 40 (8.6\%), rumors, they are not good for health by 58 (12.4\%), preferred method not available by 67 (14.3\%) and husband disapproval by 68 (14.5\%) (Figure 1). Among currently married non users 311 (66.5\%) have intention to use family planning some times in the future. The most widely intended method be injectables 228 (48.7\%) followed by pills 56 (12.0\%).

In the current study, ethnicity was found to be significantly associated with contraceptive use. Zeyse tribes were less likely to use family planning method than Gamo tribes (Adjusted Odds Ratio (AOR) $=0.211$ (0.091 0.489)). Women in the age group 25 - 29 years were about 3 times more likely to be current user than those in the age group 15 - 19 years $($ AOR $=3.047(1.387-6.693)$ ). Women's education level was shown to be significantly associated with current use of family planning. Women whose husband were government employee were found to be less likely to use family planning than those whose husband were farmer (AOR $=0.260(0.082$ $0.823)$ ). Presence of radio set in the house hold of the women is strongly associated with the current use of family planning with AOR $=0.680(0.464-0.966)$. Women who had discussed about family with their partner in 
Table 3. Percentage of all and currently married women who know, ever used and currently using any contraceptive method, by specific method, Arbaminch Zuria Woreda, 2010.

\begin{tabular}{|c|c|c|}
\hline 1) Know & $\begin{array}{l}\text { All women } \\
\text { No. (\%) }\end{array}$ & $\begin{array}{c}\text { Currently married women } \\
\text { No. (\%) }\end{array}$ \\
\hline Any method & $720(89.0)$ & 632 (90.9\%) \\
\hline Any modern method & $720(89.0)$ & $632(90.9 \%)$ \\
\hline Pill & $499(61.7)$ & 467 (62.9) \\
\hline IUD & $49(6.1)$ & $41(5.9)$ \\
\hline Injectables & $684(84.5)$ & $601(86.5)$ \\
\hline Implants & $224(27.7)$ & $200(28.8)$ \\
\hline Diaphragm/foam/jelly & $18(2.2)$ & $17(2.4)$ \\
\hline Condom & $93(11.5)$ & $70(10.1)$ \\
\hline Female sterilization & $14(1.7)$ & $8(1.2)$ \\
\hline Male sterilization & $3(0.4)$ & $2(0.3)$ \\
\hline Any traditional method & $138(17.1)$ & $118(17)$ \\
\hline Rhythm & 137 (16.9) & $117(16.8)$ \\
\hline Withdrawal & $7(0.9)$ & $7(1.0)$ \\
\hline \multicolumn{3}{|l|}{ 2) Ever use } \\
\hline Any method & $369(45.6)$ & $359(51.7)$ \\
\hline Any modern method & $365(45.1)$ & $355(51.1)$ \\
\hline Pills & $67(8.3)$ & $61(8.8)$ \\
\hline IUD & $2(0.2)$ & $2(0.3)$ \\
\hline Injectables & 318 (39.3) & $312(44.8)$ \\
\hline Implants & $30(3.7)$ & $30(4.3)$ \\
\hline Diaphragm/foam/jelly & $1(0.1)$ & $1(0.1)$ \\
\hline Condom & $4(0.5)$ & $3(0.4)$ \\
\hline Female sterilization & $1(0.1)$ & $1(0.1)$ \\
\hline Male sterilization & 0 & 0 \\
\hline Any traditional method & $30(3.7)$ & $30(4.3)$ \\
\hline Rhythm & $30(3.7)$ & $30(4.3)$ \\
\hline Withdrawal & $3(0.4)$ & $3(0.4)$ \\
\hline \multicolumn{3}{|l|}{ 3) Current use } \\
\hline Any method & $229(28.3)$ & $227(32.7)$ \\
\hline Any modern method & $228(28.2)$ & $226(32.5)$ \\
\hline Pills & $10(12.4)$ & $9(1.3)$ \\
\hline IUD & $1(0.1)$ & $1(0.2)$ \\
\hline Injectables & $196(24.2)$ & $195(28.1)$ \\
\hline Implants & $19(2.4)$ & $19(2.7)$ \\
\hline Diaphragm/foam/jelly & 0 & 0 \\
\hline Condom & $1(0.1)$ & $1(0.2)$ \\
\hline Female sterilization & $1(0.1)$ & $1(0.2)$ \\
\hline Male sterilization & $1(0.1)$ & 0 \\
\hline Any traditional method & $1(0.1)$ & $1(0.2)$ \\
\hline Rhythm & $1(0.1)$ & $1(0.2)$ \\
\hline Withdrawal & 0 & 0 \\
\hline
\end{tabular}




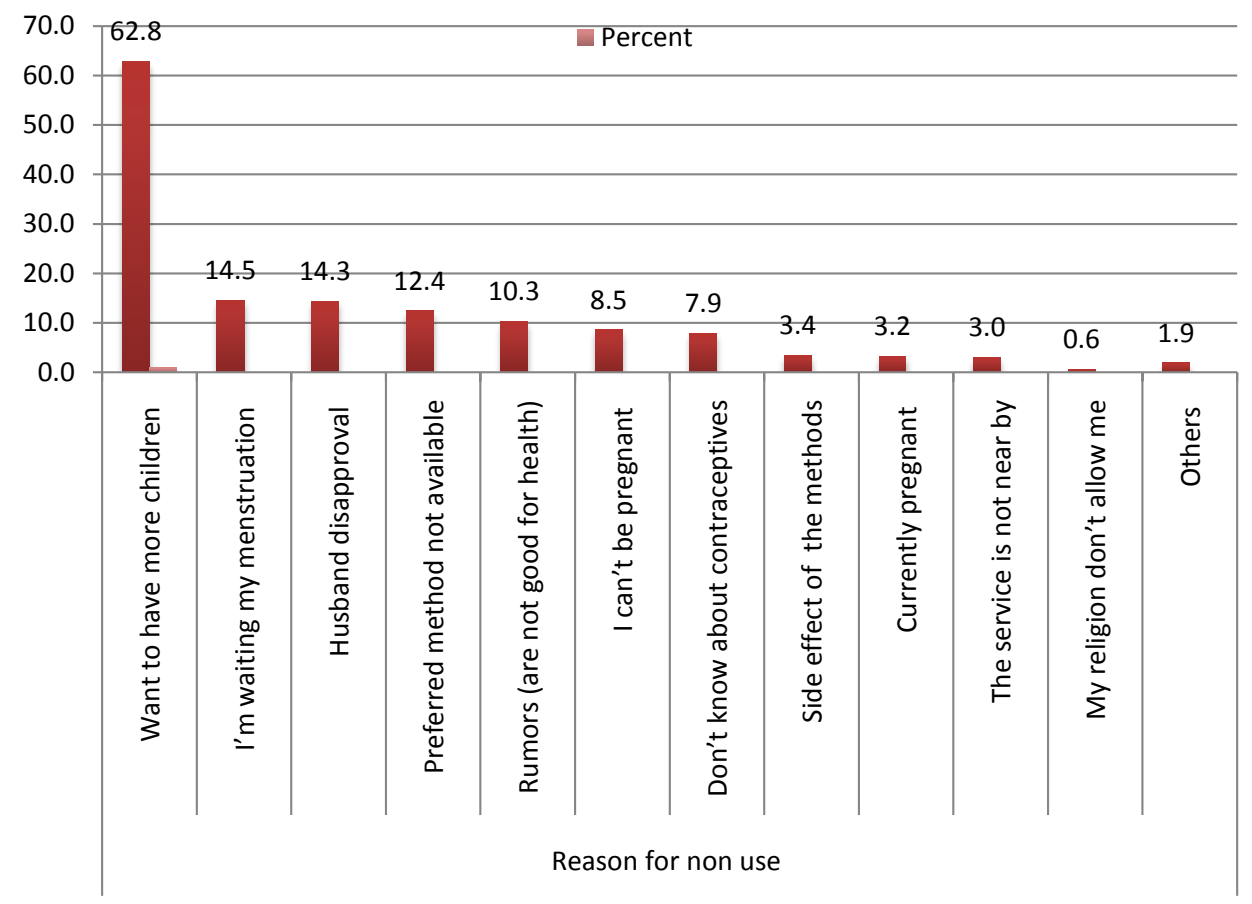

Figure 1. Percentage of currently married and current non users of any contraceptive method, by reason for non use, Arbaminch Zuria Woreda, 2010.

the last 6 months prior to the study were more likely to be current user of family planning than those did not $($ AOR $=0.259(0.169-0.395))$. Having knowledge about modern contraceptive was not significantly associated with current use of contraceptives (AOR $=0.739(0.474-1.152)$ ). Walking distance of the household from the source of the service (health facility) was not also significantly associated with current contraceptive use (Table 4 \& Table 5).

\section{Discussion}

Ever use of contraception provides a measure of the cumulative experience of a population with family planning [6]. In the current study, $45.6 \%$ of all women $\& 51.7 \%$ of currently married women were ever user of any contraceptive. This finding is relatively higher than the EDHS's 2005 report in which the rates were $18 \%$ for all women and $24 \%$ for currently married women. These higher rates of contraceptive in the current study site than the national report may be attributed to increased awareness, access to information, education and communication and family planning services as a result of the increased effort of expansion of health extension program. All the kebeles included in the study has a health post with at least one health extension workers.

The current level of contraceptive use is a measure of actual contraceptive practice at the time of the survey. Current use of family planning services provides insight into one of the principal determinants of fertility. It also serves to assess the success of family planning programmes [6]. In the current study, $28.3 \% \& 32.7 \%$ of all and currently married women, respectively, were using any contraception during the time of the survey. These findings are comparable with the finding of the studies done in northern \& eastern part of the country [7] [11]. But are higher than the EDHS's 2005 report in which the rates were $10.3 \%$ for all women and $14.7 \%$ for currently married women. This may also be because of the increased awareness and access by the health extension program mentioned above.

In the current study, except one woman all current users were using modern methods, the most widely used be injectable 196 (24.2\%) followed by implants 19 (2.4\%) and pills 9 (1.3\%). This finding is compatible with other reports/studies [6] [11] with regard to injectables as the most used method (in which injectables were the top widely used methods). But the current finding of implants as the second widely used modern method is incompatible with the findings of the other studies [6] [11], in which the second widely used method were pills. This may be due to the fact that in the current study sites especially in the kebeles near to Arba Minch Town, the im- 
Table 4. Association between current contraceptive use and socio demographic \& economic characteristics among currently married women, Arbaminch Zuria Woreda, 2010.

\begin{tabular}{|c|c|c|c|c|}
\hline \multirow{2}{*}{ Variables } & \multicolumn{2}{|c|}{$\begin{array}{l}\text { Currently married and current } \\
\text { user of family planning }\end{array}$} & \multirow{2}{*}{ COR $(95 \%$ CI) } & \multirow{2}{*}{ AOR (95\% CI) } \\
\hline & $\begin{array}{c}\text { Yes } \\
\text { No. (\%) }\end{array}$ & $\begin{array}{c}\text { No } \\
\text { No. (\%) }\end{array}$ & & \\
\hline \multicolumn{5}{|l|}{ Ethnicity $(n=695)^{@}$} \\
\hline Gamo & $186(34.4)$ & $354(65.6)$ & 1.00 & 1.00 \\
\hline Zeyse & $7(10.8)$ & 58 (89.2) & $0.230(0.103-0.513)$ & $0.211(0.091-0.489)^{*}$ \\
\hline Wolayita & $14(35.0)$ & $26(65.0)$ & $1.025(0.523-2.010)$ & $0.655(0.306-1.403)$ \\
\hline Others & $20(40.0)$ & $30(60.0)$ & $1.269(0.701-2.296)$ & $0.936(0.488-1.795)$ \\
\hline \multicolumn{5}{|l|}{ Age $(n=695)$} \\
\hline $15-19$ & $15(27.8)$ & 39 (72.2) & 1.00 & 1.00 \\
\hline $20-24$ & $49(35.8)$ & $88(64.2)$ & $1.448(0.726-2.887)$ & $1.915(0.875-4.191)$ \\
\hline $25-29$ & $63(37.5)$ & $105(62.5)$ & $1.560(0.796-3.056)$ & $3.047(1.387-6.693)^{* *}$ \\
\hline $30-34$ & $41(29.1)$ & 100 (70.9) & $1.066(0.531-2.142)$ & $2.165(0.959-4.889)$ \\
\hline $35-39$ & $34(633.0)$ & $69(67.0)$ & $1.281(0.622-2.641)$ & $2.196(0.943-5.110)$ \\
\hline $40-44$ & 17 (30.9) & 38 (69.1) & $1.163(0.509-2.656)$ & $2.404(0.919-6.291)$ \\
\hline $45-49$ & $8(21.6)$ & $29(78.4)$ & $0.717(0.268-1.918)$ & $1.803(0.585-5.560)$ \\
\hline \multicolumn{5}{|l|}{ Religion $(n=695)$} \\
\hline Protestant & $136(32.0)$ & $289(68.0)$ & 1.00 & 1.00 \\
\hline Orthodox & 85 (36.8) & $146(63.2)$ & $1.237(0.884-1.732)$ & $1.216(0.839-1.762)$ \\
\hline Others & $6(15.4)$ & 33 (84.6) & $0.386(0.158-3.944)$ & $0.575(0.225-1.470)$ \\
\hline \multicolumn{5}{|c|}{ Participant's education $(n=695)$} \\
\hline 1 = Illiterate & $114(25.3)$ & $336(74.7)$ & 1.00 & 1.00 \\
\hline $2=$ Read and write & $10(38.5)$ & $16(61.5)$ & $1.842(0.813-4.175)$ & $1.350(0.560-3.254)$ \\
\hline $3=$ Grade 1 to 6 & $59(42.1)$ & 81 (57.9) & $2.147(1.443-3.193)$ & $1.747(1.087-2.810)^{* *}$ \\
\hline $4=$ Grade 7 to 8 & $26(53.1)$ & $23(46.9)$ & $3.332(1.829-6.070)$ & $2.741(1.347-5.579)^{* *}$ \\
\hline 5 = Grade $9 \&$ above & $18(60.0)$ & $12(40.0)$ & $4.421(2.066-9.460)$ & $2.847(1.141-7.106)^{* *}$ \\
\hline \multicolumn{5}{|c|}{ Occupation of the participant $(n=695)$} \\
\hline House wife & $205(31.7)$ & $442(68.3)$ & 1.00 & 1.00 \\
\hline Others & $22(45.8)$ & $26(54.2)$ & $1.824(1.010-3.296)$ & $1.386(0.696-2.759)$ \\
\hline \multicolumn{5}{|c|}{ Husband occupation $(n=695)$} \\
\hline Farmer & $163(29.6)$ & $387(70.4)$ & 1.00 & 1.00 \\
\hline Daily laborer & $21(48.8)$ & $22(51.2)$ & $2.266(1.213-4.235)$ & $1.711(0.841-3.479)$ \\
\hline Merchant & $15(41.7)$ & $21(58.3)$ & $1.696(0.853-3.372)$ & $0.843(0.393-1.812)$ \\
\hline Government employee & $5(22.7)$ & 17 (77.3) & $0.698(0.253-1.925)$ & $0.260(0.082-0.823)^{*}$ \\
\hline Student & $8(53.3)$ & $7(46.7)$ & $2.713(0.968-7.606)$ & $0.888(0.273-2.882)$ \\
\hline Others & $15(51.7)$ & $14(48.3)$ & $2.544(1.200-5.391)$ & $1.526(0.668-3.485)$ \\
\hline \multicolumn{5}{|l|}{ Husband education $(n=695)$} \\
\hline $1=$ Illiterate & 79 (23.9) & $251(76.1)$ & 1.00 & 1.00 \\
\hline 2 = Read and write & $17(33.3)$ & $34(66.7)$ & 1.589 (0.842 - 2.997) & $1.345(0.679-2.665)$ \\
\hline $3=$ Grade 1 to 6 & 57 (31.8) & $122(68.2)$ & $1.484(0.992-2.222)$ & $1.233(0.788-1.929)$ \\
\hline $4=$ Grade 7 to 8 & $33(50.8)$ & $32(49.2)$ & 3.277 (1.894 - 5.668) & $2.430(1.316-4.487)^{*}$ \\
\hline $5=$ Grade 9 and above & $41(58.6)$ & $29(41.4)$ & $4.492(2.621-7.697)$ & $3.659(1.834-7.300)^{*}$ \\
\hline
\end{tabular}




\section{Continued}

Relative family income $(n=695)$

Very poor
Poor
Medium
Rich
Can't classify

Have radio in the house $(n=695)$

Yes
No

Walking distance of source of services

$<15$ minutes
$15-30$ minutes
$31-60$ minutes
$>60$ minutes

$\begin{array}{cc}63(29.3) & 152(70.7) \\ 62(30.2) & 143(69.8) \\ 79(38.5) & 126(61.5) \\ 14(34.1) & 27(65.9) \\ 9(31.0) & 20(69)\end{array}$

$132(40.1)$

95 (26.0)

$197(59.9)$
$271(74.0)$

$113(37.2)$

65 (35.3)

30 (25.6)

191 (62.8)

119 (64.7)

$19(21.1)$

87 (74.4)

1.00
$1.046(0.688-1.590)$
$\mathbf{1 . 5 1 3}(\mathbf{1 . 0 0 7}-\mathbf{2 . 2 7 2})$
$1.251(0.616-2.542)$
$1.086(0.469-2.514)$

$1.234(0.781-1.949)$

$1.426(0.898-2.264)$

$1.143(0.520-2.515)$

$1.374(0.554-3.407)$

1.00

$0.523(0.379$ - 0.721$)$

$0.680(0.464-0.966)^{*}$

1.00

$0.923(0.630-1.352)$

0.583 (0.362 - 0.938)

0.452 (0.259 - 0.790)
1.00

1.00

$1.022(0.675-1.546)$

$0.884(0.523-1.5491)$

0.625 (0.338 - 1.154)

${ }^{\varrho}$ To investigate the associated factors only currently married women were entertained (that is why $n=695$ instead of 809). *Adjusted to all the variables listed above. ${ }^{* *}$ Adjusted to all except husband education.

Table 5. Association between current contraceptive use and selected variables among currently married women, Arbaminch Zuria Woreda, 2002 E.C.

\begin{tabular}{|c|c|c|c|c|}
\hline \multirow{2}{*}{ Variables } & \multicolumn{2}{|c|}{$\begin{array}{c}\text { Currently married and current user } \\
\text { of family planning }\end{array}$} & \multirow{2}{*}{ COR (95\% CI) } & \multirow{2}{*}{$\operatorname{AOR}(95 \% \mathrm{CI})^{*}$} \\
\hline & $\begin{array}{c}\text { Yes } \\
\text { No. (\%) }\end{array}$ & $\begin{array}{l}\text { No } \\
\text { No. }(\%)\end{array}$ & & \\
\hline \multicolumn{5}{|c|}{ Discussion in last 6 months $(n=695)^{@}$} \\
\hline Yes & $162(48.5)$ & $172(51.5)$ & 1.00 & 1.00 \\
\hline No & $65(18.0)$ & $296(82.0)$ & $0.233(0.165-0.329)$ & $0.259(0.169-0.395)$ \\
\hline \multicolumn{5}{|c|}{$\begin{array}{l}\text { Have knowledge about modern contraceptive } \\
\text { methods ( } \geq \text { two methods) }(n=695)\end{array}$} \\
\hline Yes & $163(35.1)$ & $301(64.9)$ & 1.00 & 1.00 \\
\hline No & $64(27.7)$ & $167(72.3)$ & $0.708(0.501-1.00)$ & $0.739(0.474-1.152)$ \\
\hline \multicolumn{5}{|c|}{ Number of live children $(n=650)$} \\
\hline $1-2$ & $88(37.8)$ & $145(62.2)$ & 1.00 & 1.00 \\
\hline $3-4$ & $74(31.4)$ & $162(68.6)$ & $0.753(0.514-1.103)$ & $1.367(0.607-3.076)$ \\
\hline$\geq 5$ & 65 (35.9) & $116(64.1)$ & $0.923(0.617-1.381)$ & $1.572(0.546-4.529)$ \\
\hline \multicolumn{5}{|c|}{ Ever abortion $(n=695)$} \\
\hline Yes & $35(30.4)$ & $80(69.6)$ & 1.00 & 1.00 \\
\hline No & $192(33.3)$ & 388 (66.9) & $1.131(0.733-1.744)$ & $1.196(0.639-2.236)$ \\
\hline \multicolumn{5}{|c|}{ Ever stillbirth $(n=695)$} \\
\hline Yes & $11(37.9)$ & $18(62.1)$ & 1.00 & 1.00 \\
\hline No & $216(32.4)$ & $450(67.6)$ & $0.785(0.365-1.692)$ & $0.682(0.266-1.746)$ \\
\hline \multicolumn{5}{|c|}{ Child death $(n=695)$} \\
\hline Yes & $71(29.7)$ & $168(70.3)$ & 1.00 & 1.00 \\
\hline No & $156(34.2)$ & $300(65.8)$ & $1.230(0.877-1.726)$ & $1.633(0.933-2.859)$ \\
\hline \multicolumn{5}{|c|}{ Gravidity $(n=695)$} \\
\hline Less than one & $27(25.2)$ & $80(74.8)$ & 1.00 & 1.00 \\
\hline Two & $43(39.4)$ & $66(60.6)$ & $1.930(1.080-3.452)$ & $1.163(0.581-2.331)$ \\
\hline $3-4$ & $63(31.8)$ & $135(68.2)$ & $1.383(0.815-2.347)$ & $0.748(0.290-1.929)$ \\
\hline More than 4 & $94(33.5)$ & $187(66.5)$ & $1.489(0.902-2.460)$ & $0.772(0.217-2.739)$ \\
\hline \multicolumn{5}{|c|}{ Age at first pregnancy $(n=504)$} \\
\hline$<18$ years & $63(42.6)$ & $85(57.4)$ & 1.00 & 1.00 \\
\hline$\geq 18$ years & 115 (32.3) & $241(67.7)$ & $0.644(0.434-0.955)$ & $0.644(0.413-1.003)$ \\
\hline
\end{tabular}

${ }^{\circledR}$ To investigate the associated factors only currently married women were entertained (that is why n $=695$ instead of 809). *Adjusted to all reproductive and other variables included in the table. 
plants were being provided on a campaign and static base at health centers level. In the current study, among currently married current users $76 \%$ were using for spacing and $24 \%$ for limiting. This is incompatible with the findings of another study [14] in which the limiters (45.9\%) were larger than spacers (27.5\%). This is due to the fact that, the participants of the previous study were either long-term or permanent methods users, who are most likely to be limiter than those who are using short term methods.

As marriage marks the point in a woman's life when childbearing becomes socially acceptable, age at first marriage has a major effect on childbearing because women who marry early have on average a longer period of exposure to pregnancy and a greater number of lifetime births [6]. In the current study, $40.4 \%$ of ever married women got married for the first time before their $18^{\text {th }}$ birth date and age at first marriage ranges from 13 to 26 years with median and mode age of 18 years. The current finding is lower than that of EDHS's 2005 report in which the rate was $61.8 \%$ with median age at first marriage 16.1 years. This older age at the first marriage in the current study also may be attributed to the increased engagement of females and males in education as the school enrolment rate is reported to be increasing from time to time in the country in general and in the study area in particular.

Unintended pregnancies are the forerunners of unsafe abortions. In the current study $20.0 \%$ of the current pregnancies were mistimed or unwanted. The same proportions of the pregnancies for births within 6 months prior to the survey were mistimed or unwanted. This result was relatively lower than other studies [7] [15], in which the proportions were $33.3 \% \& 27.5 \%$, respectively. This may be due to under reporting caused by social desirable biases.

In the current study, $89.0 \%$ of all and $90.9 \%$ of currently married women know at least one contraceptive method. Modern methods are more widely known than traditional methods. For example, $90.9 \%$ percent of currently married women know of a modern method, and only $17 \%$ know of a traditional method. Relatively similar finding was observed in the EDHS 2005 survey, in which 88\% of currently married women knew at least one method of contraception, with the most widely know be modern methods.

Acquiring knowledge about family planning is assumed to be an important step towards gaining access to and using a suitable contraceptive method in a timely and effective manner. Individuals who have adequate information about the available methods of contraception are expected to be better able to make choices about planning their families [6]. But in the current study, having knowledge about modern contraceptive is not shown to be a predictor of its use. This may be explained by the misunderstanding/misconception about the methods by the community and the side effects associated with them.

In this study, among currently married non users of any contraceptive method, the most important reason, given by $62.8 \%$ respondents for not using modern contraceptives was the need to have children. This finding is also in line with other studies done in other parts of the country [11] [16]. Husband disapproval and preferred method not available were also raised by $14.5 \%$ and $14.3 \%$ of the respondents respectively as the reasons for their nonuse. The same report was observed in another study [16] in which $23.2 \%$ of the respondents mentioned husband disapproval as a reason for non use. These may be an important alert to the service providers and program managers to involve men in family planning issues and provide need based methods.

Intention to use a method of contraception is an important indicator of the potential demand for family planning services [6]. In the current study, among currently married non users 311 (66.5\%) have intention to use family planning some times in the future. The most widely intended method be injectables 228 (48.7\%) followed by pills 56 (12.0\%). This finding is in line with that of EDHS 2005. This can be used as an indicator for planning the method mix in the area.

In this study, those who were single (1.5\%) and ever married but unmarried at the time of the study (0.02\%) were less likely to be current user than those married at the time of the survey (32.7\%). Similarly the family planning utilization rate was higher among currently married women than non married women in other studies [6] [11]. This may show the importance of increasing efforts to increase the utilization of contraceptives by sexually active unmarried women, as pregnancies out of marriage are unacceptable by the society and unintended or unwanted by the mother and they usually end up with unsafe abortion. Even though only $2.1 \%$ and $16.9 \%$ of never married and married but unmarried women at the time of the EDHS 2005 survey, respectively, reported to be sexually active within one year prior of the survey time [6], the figures are expected to be higher as women who are not married usually deny to report that they are sexually active.

In the current study, ethnicity was found to be significantly associated with contraceptive use. Zeyse tribes 
were less likely to use family planning method than Gamo tribes (Adjusted Odds Ratio (AOR) $=0.211(0.091$ 0.489)). This may be due to the fact that the kebele where Zeyse tribes live is one of the farthest kebele from Arba Minch Town where most family planning services and information are expected to be easily accessible.

Women in the age group 25 - 29 years were about 3 times more likely to be current user than those in the age group 15 - 19 years (AOR = 3.047 (1.387 - 6.693)). Compatible finding was observed in the EDHS 2005 report [6], in which the prevalence of any modern contraceptive use among 25 - 29 and 15 - 19 years age groups were $14.4 \%$ and $2.5 \%$, respectively. For obvious reason, younger women are more likely to have fewer children than older woman. The number of children is the main reason mentioned for non use.

Women's education level was shown to be significantly associated with current use of family planning. As the educational status of the woman increase she is more likely to be current user of family planning methods. Relatively similar finding was observed in another study [17]. This may be due to the fact that, as woman become literate her awareness about the importance of family planning and where service is, are increased which are a driving force for her utilization. Education also expected to increase her autonomy in planning her family size.

Unexpectedly, women whose husband were government employee were found to be less likely to use family planning than those whose husband were farmer $($ AOR $=0.260(0.082-0.823)$ ). This may be due to the fact that majorities (79.15\%) of the participants' husband were farmer; whereas only $3.2 \%$ of them were government employee. Presence of radio set in the house hold of the women is strongly associated with the current use of family planning with AOR $=0.680(0.464-0.966)$. Presence of radio in the household of rural setting may be an indicator of socioeconomic status including educational status of the households. It may also be because of access of information about family planning through radio advertisements.

In this study, current use of family planning was significantly associated with experience of discussion about family planning with their partner within 6 months prior to the survey. Women who had discussed about family with their partner in the last 6 months prior to the study were more likely to be current user of family planning than those did not (AOR $=0.259$ (0.169 - 0.395)). This finding is compatible with Hosanna's study [16].

Despite for all measures to insure the quality of the data this study cannot be free of limitations. Because of its cross-sectional nature cause and effect relationships cannot be concluded based on this study. Social desirability and recall biases could be other limitations of the current study.

\section{Conclusions and Recommendations}

Even though contraceptive prevalence rate is higher than that in the national report, efforts should continue to further increase the contraceptive coverage. Since there was family planning coverage discrepancy among kebeles, special attention/effort should be exerted on those kebeles with low coverage. Injectables are the most preferred method currently and in the future, health programmers and implementers should work in meeting this increasing demand. As the demand for long-term methods is also reported to be increasing, there should be efforts to increase the accessibility of the services especially to those in the distant kebeles. Moreover, there should be increased efforts to advocate use of other methods especially those with dual benefit like condom by needy groups (unmarried sexually active women). As revealed by this study, knowledge alone is not observed to lead contraceptive use; hence, emphasis should be given to misconceptions about contraceptives and behavioral change. As husbands' disapproval was one of the main reasons for non-use (raised by the respondents and the discussants during focus group discussion), family planning programs should focus on men and address men as principal stakeholders. Involving men along with women in promoting family planning communication and information dissemination could have significant impact on increasing contraceptive rate.

As evidenced by the current study, younger women are less likely to use contraceptive. Due to belief of the society that children born at early age are healthier, women try to fulfill their required number of children as early as possible. As the number of demanded children (mean (SD) of 5.3 (1.6)) is relatively large, birth intervals are more likely to be narrow, which could have a negative effect on the children and the mother. So the health workers and other concerned bodies should work to increase awareness about the negative effect of shorter birth intervals. As education was shown to have effect on contraceptive use, the expansion of education should continue and the effort to increase female enrolment rate should also continue. As discussion between spouses on family planning matters has a positive effect on contraceptive use, efforts should be excreted to increase spousal discussion and their joint decision-makings on contraceptive use and fertility. Further study investigating the quality of the services and opinions of men are recommended. 


\section{Competing Interests}

The author has no competing interest.

\section{Author's Contribution}

Girma Temam: is the principal investigator who is responsible to all the activities starting from the inception to the final write of the paper (manuscript).

\section{Acknowledgements}

I would like to express my thanks to Arba Minch University for its financial support and keen interest without it the study would not have been materialized. I am also grateful to: Gamo Gofa Zone Health Department, Arba Minch Zuria Woreda Administration Office, Arba Minch Zuria Woreda Health Office, Officials of all the kebeles, Arba Minch Demographic and Health Development Program Coordinating Office, Ato Zemedu Mohamed, Ato Aman Yesuf, Supervisors, Data collectors and all study participants.

\section{References}

[1] WHO (2011) Statistical Information System. Contraceptive Prevalence Rate. http://www.who.int/healthinfo/statistics/indcontraceptiveprevalence/en/index.htm

[2] WHO Media Center (2013) Family Planing Fact Sheet. http://www.who.int/mediacentre/factsheets/fs351/en/

[3] The Info Project Center for Communication Programmes, The Johns Hopkins Bloomberg School of Public Health (2003) Population Reports. The Info Project Center for Communication Programmes, The Johns Hopkins Bloomberg School of Public Health, Baltimore.

[4] Ethiopian National Census Report (2007) Addis Ababa, Ethiopia.

[5] The Transitional Government of Ethiopia (1993) National Population Policy. The Transitional Government of Ethiopia, Addis Ababa.

[6] Central Statistics Agency and ORC Macro (2005) Ethiopia Demographic and Health Survey. Central Statistics Agency and ORC Macro, Addis Ababa and Calverton.

[7] Worku, S. and Fentahun, M. (2006) Unintended Pregnancy and Induced Abortion in a Town with Accessible Family Planning Service: The Case of Harar in Eastern Ethiopia. The Ethiopian Journal of Health Development, 20, 79-83.

[8] Hong, R., Montana, L. and Mishral, V. (2006) Family Planning Services Quality as a Determinant of Use of IUD in Egypt. BMC Health Services Research, 6, 79. http://dx.doi.org/10.1186/1472-6963-6-79

[9] Kamal, N., Lim, C. and Omar, R. (2005) Determinants of Contraceptive Use in the Urban Slums of Bangladesh: A Multilevel Model. http://www.census.gov/ipc/prod/wp02/wp-02005

[10] Mitike, G. (2000) Community Based Distribution of Family Planning as Perceived by People in the Reproductive Age Group, North \& South Gondar Zones, Ethiopia. The Ethiopian Journal of Health Development, 14, 31-42. http://dx.doi.org/10.4314/ejhd.v14i1.9928

[11] Kebede, Y. (2000) Contraceptive Prevalence and Factors Associated with Usage of Contraceptives around Gondar Town. The Ethiopian Journal of Health Development, 14, 327-334. http://dx.doi.org/10.4314/ejhd.v14i3.9906

[12] Kaba, M. (2000) Fertility Regulation among Women in Rural Communities around Jimma, Western Ethiopia. The Ethiopian Journal of Health Development, 14, 117-125. http://dx.doi.org/10.4314/ejhd.v14i2.9910

[13] Ali, A.A., Rayis, D.A., Mamoun, M. and Adam, I. (2000) Use of Family Planning Methods in Kassala, Eastern Sudan. BMC Research Notes $X, 4$, 43. http://www.biomedcentral.com/1756-0500/4/43

[14] Asnake, M., Walie, L. and Melkamu, Y. (2006) Improving the Range of Contraceptive Choices in Rural Ethiopia. The Ethiopian Journal of Health Development, 20, 74-78.

[15] Igwegbe, A.O., Ugboaja, J.O. and Monago, E.N. (2009) Prevalence and Determinants of Unmet Need for Family Planning in Nnewi, South-East Nigeria. International Journal of Medicine and Medical Sciences, 1, 325-329.

[16] Tuloro, T., Deressa, W., Ali, A. and Davey, G. (2006) The Role of Men in Contraceptive Use and Fertility Preference in Hossana Town, Southern Ethiopia. The Ethiopian Journal of Health Development, 20, 152-159.

[17] Jain, D.C. (1997) Family Planning Use and Its Determinants among Gond Tribe of Madhya Pradesh: A Case Study of Gonds of Jabalpur District. Proceeding of National Symposium on Tribal Health, 285-292.

http://www.rmrct.org/files_rmrc_web/centre's_publications/NSTH_06/NSTH06_35.DC.Jain.pdf 


\section{List of Abbreviations}

COR: Crude Odds Ratio

CPR: Contraceptive Prevalence Rate

EDHS: Ethiopian Demographic and Health Survey

FGD: Focus Group Discussion

HH: House Hold

HIV: Human Immunodeficiency Virus

MDGs: Millennium Development Goals

OR: Odds Ratio

SD: Standard Deviation

SNNPR: Southern Nation Nationalities People Region

TFR: Total Fertility Rate 